\title{
UM ESTUDO SOBRE A VIABILIDADE DA UTILIZAÇÃO DE UM PROGRAMA DE MELHORIA DE PROCESSO DE SOFTWARE EM PEQUENAS EMPRESAS
}

\section{A STUDY ABOUT THE FEASIBILITY OF USING AN SOFTWARE PROCESS IMPROVEMENT PROGRAM AT MICRO AND SMALL COMPANIES}

\author{
Renan Lirio de Souza ${ }^{1}$ \\ DCEEng, Universidade Regional do Noroeste do Estado do Rio Grande do Sul (UNIJUI) \\ - RS - Brasil ${ }^{1}$ \\ E-mail: suzanalirio@msn.com ${ }^{1}$
}

RESUMO - Este artigo apresenta um estudo sobre a viabilidade de utilização do programa MPS.BR em micro e pequenas empresas (MPEs). Foi realizada uma pesquisa envolvendo 13 MPEs de desenvolvimento de software, com o intuito de coletar dados a respeito das experiências vividas durante a implementação e utilização do programa. Estes dados foram organizados e classificados com base em fatores determinantes de sucesso e dificuldades, cuja análise, comparada com o resultado de outros pesquisadores, identifica a importância e viabilidade de sua utilização.

Palavras-chave: melhoria de software; MPS.BR; pequenas empresas.

\begin{abstract}
This paper presents a study on the feasibility of using the MPS.BR program at micro and small enterprises (MSEs). A survey was conducted involving $13 \mathrm{MSEs}$ of software development in order to collect data about the experiences during the implementation and use of the program. These data were organized and classified based on determinants of success and difficulties, whose analysis, in comparison to the results of other researchers, identify the importance and feasibility of its use.

Keywords: software improvement; MPS.BR; small companies.
\end{abstract}

Recebido em: 30/04/2016 Revisado em: 21/09/2016 Aprovado em: 08/11/2016 


\section{INTRODUÇÃO}

Atualmente, com a crescente demanda de produção de softwares, a concorrência entre as empresas desenvolvedoras vem aumentando significativamente, o que exige por parte delas a necessidade de aperfeiçoar seu processo de desenvolvimento. Diversos modelos e programas para melhoria de desenvolvimento, baseados em técnicas de engenharia de software, surgiram com 0 intuito de auxiliar estas empresas. De maneira geral, eles englobam toda a documentação, configuração, métodos de desenvolvimento e inúmeras outras técnicas voltadas para melhoria do desenvolvimento (SOMMERVILLE, 2003).

Dentre as opções disponíveis estão as normas ISO/IEC e os programas de melhoria CMMI e MPS.BR. As normas ISO/IEC e o CMMI são voltados para empresas de maior porte (ANACLETO et al., 2004; LAPORTE et al., 2008). Já o MPS.BR possui maior aplicação em micro, pequenas e médias empresas, embora seja possível adequá-lo ao perfil de empresas com diferentes tamanhos e características, sejam públicas ou privadas (SOFTEX, 2016).

Ambos os modelos já são amplamente utilizados, entretanto a adoção dos programas para melhoria de desenvolvimento em MPEs ainda é um desafio prático, uma vez que diferentes empresas, por possuírem características distintas, irão necessitar de esforços específicos (ANACLETO et al., 2004). Sendo assim, são necessários estudos de caso em diferentes cenários para a definição de uma melhor estratégia de implementação (ROCHA et al., 2006).

Os trabalhos de Anacleto et al. (2004) e Laporte et al. (2008) ressaltam a importância de estudos voltados a empresas de micro e pequeno porte. Com o intuito de colaborar com esses estudos foi desenvolvida uma pesquisa do tipo survey, direcionada somente a este perfil de empresas. Participaram da pesquisa 13 empresas de micro e pequeno porte, localizadas em diferentes regiões do país, principalmente no Rio Grande do Sul, São Paulo, Santa Catarina, Paraná e uma em Pernambuco. O objetivo foi identificar os principais fatores determinantes de sucesso e dificuldades experimentados por estas MPEs e comparálos com os mesmos enfrentados por empresas de maiores portes (ROCHA et al., 2006). Com isso, foi possível identificar as diferenças nos resultados da utilização do programa MPS.BR em razão do seu porte e, por fim, a viabilidade de sua utilização.

O presente artigo está estruturado nas seguintes seções: a Seção 2 apresenta os estudos relacionados, onde são destacadas algumas pesquisas utilizadas 
como embasamento; na Seção 3 é discutida a metodologia de survey utilizada no trabalho; a Seção 4 contempla os principais resultados obtidos pela pesquisa; por fim, na Seção 5 são apresentadas as considerações finais.

\section{ESTUDOS RELACIONADOS}

Um survey realizado com o intuito de identificar fatores de sucesso e dificuldades relacionados à implementação de processos de software, utilizando o MR-MPS e o CMMI foi elaborado por Rocha et al. (2006). Sua pesquisa envolveu 15 empresas da área de desenvolvimento de software. Como resultado, são identificadas boas práticas que podem ser adotadas na definição da estratégia de implementação e acompanhamento de processos de software por instituições implementadoras do MRMPS no Brasil.

Anacleto et al. (2004) desenvolveram uma pesquisa que descreve experiências de 4 empresas desenvolvedoras de software com a aplicação da norma ISO/IEC 15504. Neste trabalho foram relatados os problemas enfrentados por empresas de pequeno porte que desejam utilizar métodos para melhoria do seu processo. Como forma de reduzir o esforço adicional e melhor atender seus requerimentos específicos, um método de melhoria customizado está sendo desenvolvido no projeto de pesquisa chamado 15504MPE, adaptado para as características e necessidades próprias das pequenas companhias.

Laporte et al. (2008) conduz um estudo onde demonstra que a norma ISO/IEC12207 não é voltada para MPEs, que em geral acham difícil entendê-la. A pesquisa apresenta os resultados obtidos na busca pelo desenvolvimento de uma nova norma, baseada na ISO/IEC12207, que atenda micro e pequenas empresas. Estes resultados possibilitam definir os requerimentos necessários para o design de uma nova norma, voltada especificamente a este tipo de empresas.

\section{MÉTODO DE PESQUISA SURVEY}

$\mathrm{Na}$ fase inicial do trabalho foi realizada uma busca por micro e pequenas empresas desenvolvedoras de software que utilizavam ou estavam em fase de implantação do programa MPS.BR. Foi encaminhado a elas um questionário, via email, o qual deveria ser preenchido com informações referentes às experiências vividas durante a implementação e uso. As perguntas buscavam identificar os fatores positivos e negativos proporcionados pela adesão ao programa, como por exemplo, os benefícios ou dificuldades enfrentadas pelas organizações. Ver Tabela 1 e a Tabela 2. 
Tabela 1. Exemplo das questões contidas no questionário.

\section{QUESTIONÁRIO}

Vocês utilizam alguma norma ou método para melhoria de desenvolvimento?

Qual o motivo da escolha do método, em específico, citado anteriormente?

Quais os motivos para a adoção?

Qual a quantidade de funcionários da empresa?

Como são classificadas as atividades propostas?

Quais técnicas de desenvolvimento eram usadas antes da adoção?

Quais foram as dificuldades iniciais?

Tabela 2. Exemplo das respostas obtidas pelo questionário.

\begin{tabular}{|c|c|c|c|c|}
\hline \multirow{2}{*}{ Questão } & \multicolumn{4}{|c|}{ Exemplo das respostas de algumas empresas } \\
\hline & Empresa 01 & Empresa 02 & Empresa 03 & Empresa 04 \\
\hline Dificuldade inicial & $\begin{array}{l}\text { Obter a credibilidade } \\
\text { da equipe de que a } \\
\text { implantação nos } \\
\text { ajudaria a resolver } \\
\text { boa parte dos nossos } \\
\text { problemas. }\end{array}$ & $\begin{array}{l}\text { Definir o processo de } \\
\text { para atender as } \\
\text { evidencias de projeto } \\
\text { não onerando o } \\
\text { trabalho da equipe } \\
\text { de forma } \\
\text { burocrática. }\end{array}$ & $\begin{array}{l}\text { Mudança na cultura } \\
\text { da empresa; não } \\
\text { tínhamos nenhuma } \\
\text { estrutura de } \\
\text { processo e nem } \\
\text { documentação } \\
\text { formal. }\end{array}$ & $\begin{array}{l}\text { Entendimento do } \\
\text { modelo e adaptação } \\
\text { dos resultados } \\
\text { esperados. }\end{array}$ \\
\hline Aceitação & $\begin{array}{l}\text { De início houve } \\
\text { resistência, devido } \\
\text { ao trabalho adicional } \\
\text { e descrença. Equipe } \\
\text { técnica não vê valia } \\
\text { em processos de } \\
\text { gestão, procurando } \\
\text { se focar na } \\
\text { codificação. }\end{array}$ & $\begin{array}{l}\text { Bons, todos os } \\
\text { setores participaram } \\
\text { da construção dos } \\
\text { processos. }\end{array}$ & $\begin{array}{l}\text { Nossa equipe é } \\
\text { jovem com poucos } \\
\text { "vícios" de processos } \\
\text { anteriores, } \\
\text { facilitando no } \\
\text { entendimento e } \\
\text { absorção. }\end{array}$ & $\begin{array}{l}\text { Início difícil, mas com } \\
\text { o passar do tempo, } \\
\text { houve } \\
\text { amadurecimento da } \\
\text { equipe. Alguns } \\
\text { membros da equipe } \\
\text { deram opiniões } \\
\text { quanto ao processo } \\
\text { de trabalho. }\end{array}$ \\
\hline Criticas ao modelo & $\begin{array}{l}\text { Não houve críticas } \\
\text { formais, mas dava } \\
\text { para perceber o } \\
\text { desconforto dos } \\
\text { envolvidos e a } \\
\text { descrença no } \\
\text { modelo. }\end{array}$ & Algumas pela equipe & Nenhuma & $\begin{array}{l}\text { Perda de agilidade do } \\
\text { processo de trabalho. }\end{array}$ \\
\hline
\end{tabular}


Tabela 2. Exemplo das respostas obtidas pelo questionário. (continuação)

\begin{tabular}{|c|c|c|c|c|}
\hline \multirow{2}{*}{ Questão } & \multicolumn{4}{|c|}{ Exemplo das respostas de algumas empresas } \\
\hline & Empresa 01 & Empresa 02 & Empresa 03 & Empresa 04 \\
\hline $\begin{array}{l}\text { Comparação com } \\
\text { métodos antigos }\end{array}$ & $\begin{array}{l}\text { Sensível melhora na } \\
\text { definição de } \\
\text { requisitos e em } \\
\text { estágio de pré- } \\
\text { venda; } \\
\text { Queixas de cliente } \\
\text { quanto ao escopo do } \\
\text { projeto foram } \\
\text { reduzidas } \\
\text { praticamente a zero. }\end{array}$ & Sim & $\begin{array}{l}\text { Sim. Não tinha } \\
\text { processo, era tudo } \\
\text { em planilhas Excel e } \\
\text { com os dois sócios da } \\
\text { empresa. } \\
\text { Melhoramos } \\
\text { bastante, hoje temos } \\
\text { todo o controle do } \\
\text { nosso processo } \\
\text { produtivo. }\end{array}$ & $\begin{array}{l}\text { Continuamos tendo } \\
\text { alguns problemas. Os } \\
\text { processos descritos } \\
\text { pela MPS.BR fizeram } \\
\text { com que o } \\
\text { planejamento e } \\
\text { tomada de ações } \\
\text { fosse mais rápido e } \\
\text { assertivos. }\end{array}$ \\
\hline $\begin{array}{l}\text { O que mudou e o } \\
\text { que foi mantido }\end{array}$ & $\begin{array}{l}\text { Não tínhamos um } \\
\text { processo formal } \\
\text { definido; } \\
\text { Cada um trabalhava } \\
\text { do jeito em que } \\
\text { estava acostumado. }\end{array}$ & $\begin{array}{l}\text { Praticamente todo o } \\
\text { processo foi } \\
\text { remodelado }\end{array}$ & $\begin{array}{l}\text { Tudo, não existia } \\
\text { processo definido. } \\
\text { Nada foi mantido }\end{array}$ & $\begin{array}{l}\text { Uma melhora no } \\
\text { gerenciamento e } \\
\text { visualização dos } \\
\text { resultados. Isso pode } \\
\text { ser mantido. }\end{array}$ \\
\hline
\end{tabular}

Dentre as cerca de 120 empresas procuradas, apenas 13 se dispuseram a participar da pesquisa. 12 delas retornaram o questionário de forma adequada. A outra empresa disponibilizou um funcionário para realizar uma entrevista e responder as questões diretamente ao pesquisador. Cabe salientar que esta ultima foi a única empresa que não conseguiu a certificação, sendo que a entrevista foi realizada com o intuito de melhor descrever as principais dificuldades encontradas na implementação da metodologia. As respostas obtidas pela entrevista relataram, da mesma forma que as respostas via e-mail, os fatores positivos e negativos vivenciados pela empresa.

\subsection{Caracterização das empresas}

De acordo com os dados, do total das 13 empresas, 7 possuem entre 0-9 empregados, 4 possuem entre $10-15$ e 2 possuem entre $16-25$, como mostra a Figura 1. 


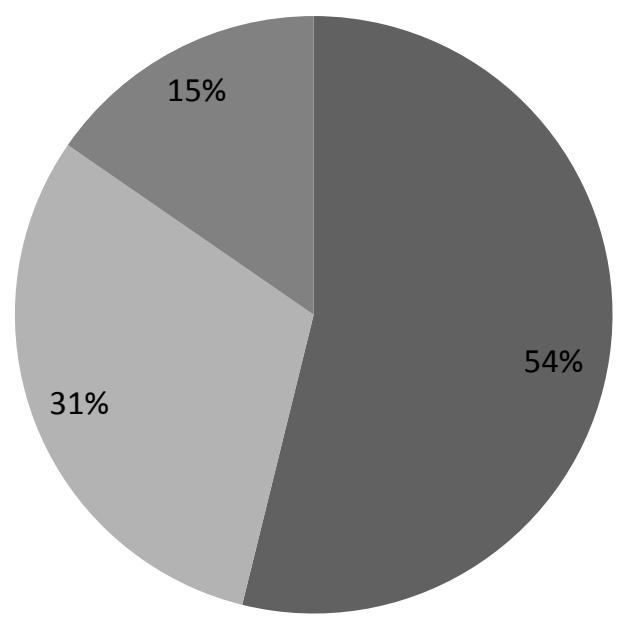

- 0-9 empregados $\quad$ 10-15 empregados

- 16-25 empregados

Figura 1. Quantidade de funcionários das empresas pesquisadas.

O critério usado para caracterizar o porte das empresas participantes foi o do SEBRAE (2014), que se baseia nas fontes fornecidas pelo IBGE, referente ao número de empregados, a saber: micro (0-9 empregados); pequena (10-49 empregados); média (50-99 empregados); grande(mais de 100 empregados).

Além do tamanho das empresas, foi mapeado o seu atual nível de maturidade. Entre as participantes, 10 estão no nível G, 2 no nível $F$ e uma das empresas não conseguiu obter a certificação. Ver figura 2.

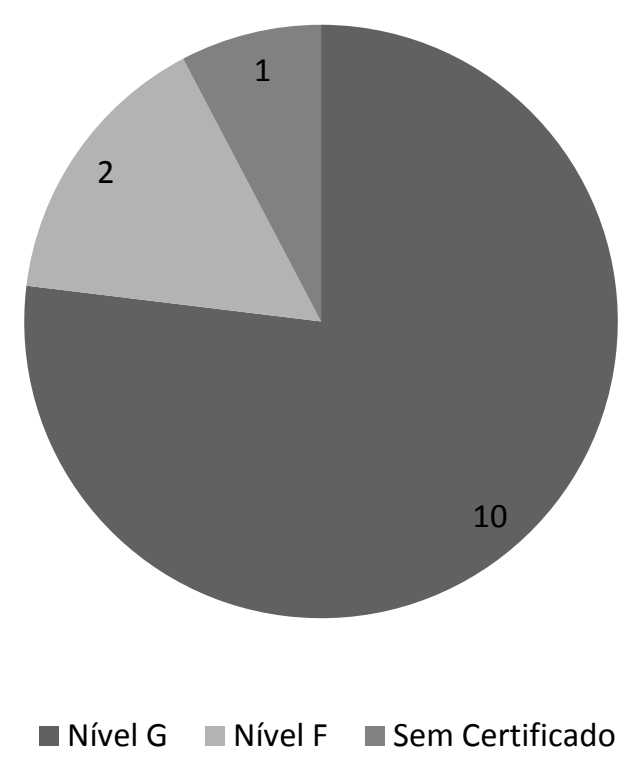

Figura 2. Nível de maturidade das empresas pesquisadas.

\section{RESULTADOS E DISCUSSÕES}

Os resultados, obtidos via questionário e entrevista, passaram por uma análise de conteúdo e foram estruturados nos seguintes itens: fatores determinantes de sucesso e principais dificuldades ou desafios encontrados na implantação. Os principais achados, considerados de maior relevância, são apresentados a seguir.

\subsection{Fatores determinantes de sucesso}

Um dos fatores mais importantes relacionado ao sucesso se refere à questão organizacional da empresa. Segundo a pesquisa, $90 \%$ das empresas não possuíam nenhuma forma de metodologia ou rotina para documentação e gerenciamento dos projetos. Com a adoção de programas de 
melhoria de software, surgiu a necessidade de definição de funções antes inexistentes, pois a estruturação da equipe, definição e distribuição de tarefas tem grande influência no sucesso como um todo. A maioria das empresas pesquisadas demonstrou maturidade neste quesito, definindo os papéis e transferindo as tarefas adequadamente.

$$
\text { O segundo ponto percebido }
$$
nos resultados se refere ao envolvimento e motivação dos colaboradores. Os resultados foram positivos quando a maioria dos funcionários estava motivada a aderir à nova rotina, a novas ferramentas e processos propostos. Além disso, se mostrou importante o apoio da gerência não só na questão financeira (treinamentos, incentivos), mas presencialmente, demonstrando envolvimento e interesse nas atividades e resultados perseguidos.

Outro ponto importante diz respeito à Consultoria. Em todos os casos, o acompanhamento de uma equipe especializada na implantação do modelo foi fundamental, sendo afirmado pelos pesquisados que sem esta equipe dificilmente seria possível a implantação e utilização do programa MPS.BR. A principal função da consultoria aconteceu através da transferência de conhecimentos, auxiliando quanto à definição e entendimento de processos, agilizando o trabalho e o tornando mais produtivo.

\subsection{Principais dificuldades e desafios encontrados}

A primeira dificuldade está relacionada ao entendimento dos processos do programa. Muitas empresas não conseguiam entender seu funcionamento, adaptá-los a um padrão, especificar requisitos, definir e desenvolver a documentação necessária, dentre outros. Mesmo com a utilização dos guias a dificuldade persistiu, pois os seus dados foram considerados complexos e pouco exemplificados. Talvez essa dificuldade seja oriunda da falta de conhecimentos específicos de engenharia de software, ou falta de competência por parte dos implementadores.

Outro aspecto considerado negativo foi a cobrança quanto à funcionalidade de todos os processos existentes. A documentação exigida foi considerada excessiva e muitas vezes inútil, tornando as atividades muito burocráticas e diminuindo a agilidade, por consumirem o tempo que seria gasto no desenvolvimento. Em se tratando de pequenas empresas, alguns processos se mostraram de pouca utilidade ou não condizentes com a sua realidade. Mesmo assim elas não podiam ignorá-los e fazer uso apenas dos mais benéficos, pelo fato dos mesmos serem 
indispensáveis para obter e manter a certificação.

Outro fator considerado dificultador, e que teve grande número de citações pelas empresas pesquisadas, foi relacionado à mudança de cultura e a aceitação por parte dos funcionários. Quando a empresa adere ao modelo ou quando evolui de nível ocorre a incorporação de novos processos e, até mesmo, novas ferramentas passam a ser utilizadas. A necessidade de adequar os funcionários a essa nova rotina, e o trabalho adicional incorporado, tornou-se a principal causa do descontentamento e descrença por parte deles.

\subsection{Fatores de insucesso na empresa não certificada}

A empresa não conseguiu se adequar a alguns processos e ao modo de documentação do modelo, sendo declarado que a sua maneira de desenvolver era mais ágil, diferente do proposto pelo programa. Exemplificando, o desenvolvimento de projetos pequenos passou de uma semana para um (01) mês, devido a exigências de documentação.

Em relação à motivação dos funcionários e gerência, foi declarado que a direção apenas arcou com os custos, não participando do processo de implementação. Com isso, houve a falta do papel do líder, tanto para amenizar brigas e divergências entre os funcionários, quanto para demonstrar as melhorias e os benefícios propostos.

Foram relatados problemas quanto à mudança de cultura e aceitação dos funcionários. Houve muito atrito em razão das novas práticas e regras que estavam sendo introduzidas. Destaca-se a introdução de programas para documentação e controle das atividades dos funcionários. Como anteriormente eles tinham mais liberdade para desenvolver suas atividades, houve um descontentamento geral. Além disso, quando os funcionários envolvidos não viam relevância em alguns processos cobrados pelo modelo MPS, simplesmente não os executavam.

Os guias foram considerados confusos e não foi possível identificar neles os resultados esperados, faltando, segundo observado, exemplos mais claros.

A consultoria especializada contratada foi avaliada como inexperiente, não conseguindo auxiliar no processo de implantação por não possuir o conhecimento necessário para entendimento do modelo. Ainda foi relatado que a principal atividade exercida pela equipe contratada foi apenas listar os deveres da empresa, normas e processos a se aplicar, sem nenhuma assessoria ou acompanhamento.

Apesar de não conseguir a certificação e ter enfrentado inúmeros 
problemas, grandes benefícios e experiências positivas foram obtidos com a tentativa de implantação do modelo. Alguns processos foram adaptados e aplicados com sucesso, o que melhorou a forma com que a empresa passou a lidar com a organização e documentação dos softwares desenvolvidos.

\section{CONSIDERAÇÕES FINAIS}

O trabalho apresentou os resultados de uma pesquisa com MPEs desenvolvedoras na área de TI. Seu objetivo foi identificar os fatores determinantes de sucesso e dificuldades na implementação do programa MPS.BR, bem como sua utilização e viabilidade, em comparação com outros portes de empresas. Foram relatadas experiências no âmbito de 13 organizações, dentre as quais apenas uma não obteve a certificação no modelo.

Conforme os resultados obtidos no âmbito das MPEs, percebe-se que a ocorrência dos fatores determinantes de sucesso e dificuldades encontrados na literatura e em estudos relacionados (ROCHA et al., 2006), voltados a empresas de todos os portes, não diferem dos resultados relatados nesta pesquisa.

Assim, pode-se deduzir que as experiências verificadas na implantação e utilização do programa MPS.BR por grandes empresas são bastante semelhantes às vivenciadas pelas de pequeno porte.
Ainda se observa que até mesmo uma pequena empresa que falhou na implantação obteve resultados positivos. A partir dessas constatações, pode-se concluir que o programa é uma excelente alternativa para auxiliar no alcance da excelência nos processos de produção. A sua viabilidade é demonstrada, principalmente, pela experiência e benefícios proporcionados quando de sua utilização.

\section{REFERÊNCIAS}

ANACLETO, A. et al. Experiences Gained from Applying ISO/IEC 15504 to Small Software Companies in Brazil. Itajaí: Universidade do Vale do Itajaí, 2004.

LAPORTE, C. et al. The Development of International Standards for Very Small Enterprises. IEEE Computer, v. 41, n.3, mar. 2008.

ROCHA, A. et al. Fatores de sucesso e dificuldades na implementação de processos de software utilizando o MR-MPS e o CMMI. Rio de Janeiro: COPPE/UFRJ, 2006.

SEBRAE. Critérios de classificação de empresas: mei - me - epp. 2014. Disponível em: $\quad<$ http://www.sebraesc.com.br/leis/default. asp?vcdtexto=4154>.

SOFTEX. Softex MpsBR - Guia Geral MPS de Software. 2016. Disponível em: <http://www.softex.br/wpcontent/uploads/2016/04/MPS.BR_Guia_Ger al_Software_2016-com-ISBN.pdf>.

SOMMERVILLE, I. Engenharia de software. 6 . ed. São Paulo: Pearson, 2003. p. 05-12. 